\title{
Identifying Differential Tissue Response in Grape (Vitis riparia) During Induction of Endodormancy Using Nuclear Magnetic Resonance Imaging
}

\author{
Anne Fennell ${ }^{1}$ \\ Horticulture, Forestry, Landscape and Parks Department, South Dakota State University, Brookings, \\ SD 57007 \\ Michael J. Line \\ U.S. Department of Agricultural Research Service, Beltsville Agricultural Research Center, BARC-West, \\ Beltsville, MD 20705
}

ADDITIONAL INDEX WORDS. MRI, Vitis riparia, dormancy, budbreak

\begin{abstract}
Physiological and biophysical changes were monitored during shoot maturation and bud endodormancy induction in grape (Vitis riparia Michx.) under controlled environments. Growth, dry weight (DW), periderm development, bud endodormancy, and nuclear magnetic resonance imaging (MRI) $T_{2}$ relaxation times were monitored at 2, 4, or 6 weeks of long-photoperiod [long day (LD), 15 h, endodormancy inhibition] or short-photoperiod [short day (SD), 8 $\mathrm{h}$, endodormancy induction] treatments at $15 / 9 \mathrm{~h}$ day/night thermoperiod of $25 / 20 \pm 3{ }^{\circ} \mathrm{C}$. Shoots on LD plants grew throughout the entire study period, although the rate of growth decreased slightly during the 6th week. Shoot growth slowed significantly after 2 weeks of SD, was minimal by the 4th week of SD and most of the shoot tip meristems had abscised after 6 weeks of SD. Endodormancy was induced after 4 weeks of SD. DW of the stem and buds increased with increasing duration of LD and SD. While bud DW increased more under SD than LD, stem DW increased more under LD than SD. $T_{2}$ relaxation times were calculated from images of transverse sections of the grape node. There was a slight decrease in the $T_{2}$ times in the node tissues with increased duration of LD treatment, whereas SD induced a significant decrease in $T_{2}$ times during endodormancy induction. $T_{2}$ values for the node decreased after 4 weeks of SD, coinciding with endodormancy induction. Separation of node tissues into bud, leaf gap, and the remainder of the stem and analysis of the proportion of short and long $T_{2}$ times within those tissues indicated differential tissue response. A greater proportion of short $T_{2}$ times were observed in the 2-week SD leaf gap tissue than in the $L D$ and the proportion of short $T_{2}$ times continued to increase with subsequent SD treatment. Bud and all other stem tissues had a greater proportion of short $T_{2}$ times after 4 weeks of SD, coinciding with bud endodormancy induction. The proportion of short and long $T_{2}$ times in a tissue was a better indicator of endodormancy than the averaged $T_{2}$ time for the tissue. Thus, MRI allows nondestructive identification of differential tissue response to photoperiod treatments and makes it possible to separate normal vegetative maturation responses from endodormancy induction.
\end{abstract}

Woody plant bud dormancy can be separated into several stages as determined by physiological responses of the plant. Lang (1987) identified these phases as paradormancy (correlative inhibition, where growth is inhibited by endogenous plant factors outside the bud), endodormancy (deep dormancy or rest, where growth inhibition is internal to the bud and growth will resume only after exposure to a species-specific period of low temperatures), and ecodormancy (where the chilling requirement has been fulfilled and growth inhibition is due to unfavorable environmental conditions). The mechanisms controlling paradormancy and ecodormancy have been characterized; however, the controlling mechanisms for endodormancy are still being sought (Faust et al., 1997a).

Noting significant changes in the state of water in woody buds at various dormancy stages, Faust et al. (1991, 1997a) proposed that one mechanism controlling dormancy may be the state of the water. The state of water in biological materials is determined by

Received for publication 31 Aug. 2000. Accepted for publication 8 Aug. 2001 South Dakota State University journal series 3209. This paper is based upon research supported in part by the National Science Foundation under grant OSR9452894, the South Dakota Future Fund, South Dakota Research Support Fund, and the South Dakota State University Agricultural Experiment Station Funds. We thank Tony H.H. Chen for reviewing this manuscript. The cost of publishing this paper was defrayed in part by the payment of page charges. Under postal regulations, this paper therefore must be hereby marked advertisement solely to indicate this fact.

${ }^{1}$ Corresponding author. relaxation characteristics in relation to the molecular motion of the protons. The motional freedom is affected by the degree of association of water to macromolecules. Water that is free, not associated with macromolecules, relaxes slowly and has longer $\mathrm{T}_{1}$ (longitudinal) and $\mathrm{T}_{2}$ (transverse) relaxation times. Water that is "bound," structured, or closely associated with macromolecules, has shorter $\mathrm{T}_{1}$ and $\mathrm{T}_{2}$ times (Faust et al., 1997a, 1997b; Walter et al., 1992).

Changes in the state of water have been related with bud dormancy in several woody plants (Faust et al., 1991; Gardea et al., 1994; Liu et al, 1993; Parmentier et al., 1998; Rowland et al., 1992; Sugiura et al., 1995). In peach [Prunus persica (L.) Batsch (Peach Group)] flower buds, two different populations of $\mathrm{T}_{1}$ relaxation times (slow and fast) were identified by nuclear magnetic resonance (NMR) and an increase in the proportion of slow or long $\mathrm{T}_{1}$ times was related with development of ecodormancy. In wine grape (Vitis vinifera $\mathrm{L}$.), the NMR signal was too low to detect in individual buds, but $\mathrm{T}_{2}$ times in pooled endodormant bud samples were short and $\mathrm{T}_{2}$ times increased during the transition to ecodormancy (Gardea et al., 1994). In native grape (V. riparia), the $T_{1}$ and $T_{2}$ times determined by NMR in individual buds decreased during the induction of bud endodormancy (Fennell et al., 1996).

In apple [Malus sylvestris (L.) Mill. var. domestica (Borkh.) Mansf.] vegetative buds, nuclear magnetic resonance imaging (MRI) was used to detect changes in the state of water during 
transition from paradormancy to growth upon removal of apical dominance in the summer or during transition from endodormancy to ecodormancy (Buban and Faust, 1995; Faust et al., 1995; Liu et al., 1993; Wang et al., 1994). In endodormant apples very short $\mathrm{T}_{2}$ times ( $<10 \mathrm{~ms}$ ) were indicative of mostly bound water during endodormancy, while long $\mathrm{T}_{2}$ times (15 to $25 \mathrm{~ms}$ ) were related with fulfillment of the chilling requirement and the end of endodormancy (Buban and Faust, 1995; Faust et al., 1991, 1995). In blueberry (Vaccinium corymbosum L. and Vaccinum, section Cyanncoccus), the very short $\mathrm{T}_{2}$ relaxation times in endodormant buds, indicated a greater degree of bound water. An increase in $\mathrm{T}_{2}$ times upon fulfillment of chilling requirement and the greater proportion of longer $\mathrm{T}_{2}$ times in the buds when ecodormancy was ended indicated a shift to free water (Parmentier et al., 1998; Rowland et al., 1992.). In endodormant peach buds, the proportion of short $\mathrm{T}_{2}$ relaxation times was greater than that with long $\mathrm{T}_{2}$ times (Erez et al., 1998).

Thus, very short $T_{2}$ times, indicating reduction in free water and an increase in bound water, have been suggested as a criterion for development of endodormancy. Most of the peach, blueberry, and apple MRI concentrated on chilling requirement fulfillment and the transition from endodormancy to ecodormancy (dormancy breaking), rather than the transition from paradormancy to endodormancy (dormancy induction). Nevertheless, results from the paradormant apple and grape bud studies imply that a change in the state of bud water (from free to bound) could be associated with transition from paradormancy to endodormancy at the end of a growing season (Faust et al., 1991; Fennell et al., 1996; Liu et al., 1993; Wang et al., 1994).

MRI provides both anatomical and biophysical information allowing differential tissue responses to be detected. However, previous MRI studies in apple, peach, and blueberry were focused predominately on the vegetative or floral buds (Erez et al., 1998; Faust et al., 1995; Parmentier et al., 1998; Rowland et al., 1992; Sugiura et al., 1995). Therefore, the present study was undertaken to determine whether changes in the state of water are associated with endodormancy induction in the mixed bud of grapes. Physiological, physical, and anatomical data were combined to assess and separate tissue maturation and endodormancy factors. Short photoperiods (short day, SD) were used to induce bud endodormancy in $V$. riparia while long photoperiods (long day, LD) were used to inhibit endodormancy induction under warm temperatures in a controlled environment. This system allowed testing of uniform-age materials without the confounding effects of low temperature that are found under natural environmental conditions. $\mathrm{T}_{2}$ images and analysis of $\mathrm{T}_{2}$ relaxation times were used to evaluate whether changes in state of water in different node tissues were related with endodormancy induction or tissue maturation.

\section{Materials and Methods}

Plant materials. Two-year-old, spur-pruned vines of $V$. riparia (clone origin: Manitoba, Canada, lat. $52^{\circ} \mathrm{N}$ ) were grown for these studies. In mid-March 1995, two hundred forty ecodormant vines with three or four spurs were placed in 15-L containers with media consisting of a mixture of 1 soil: 2 peat: 2 perlite (by volume). Three or four shoots (one on each spur) were trained vertically on each plant and all flower clusters were removed (Fennell et al., 1996). Plants were grown under LD (15 h) at day/ nights $(\mathrm{D} / \mathrm{N}) 25 / 20 \pm 3{ }^{\circ} \mathrm{C}$ with a 600 to $1400 \mu \mathrm{mol} \cdot \mathrm{m}^{-2} \cdot \mathrm{s}^{-1}$ photosynthetic photon flux $(P P F)$, in a climate-controlled un- shaded glass greenhouse (En Tech Control Systems, Inc., Montrose, Minn.) from March through May 1995 in Brookings, S.D. (lat. $\left.42^{\circ} \mathrm{N}\right)$. High pressure sodium lamps $(400 \mathrm{~W})$ were used to extend daylength to $15 \mathrm{~h}$ (March through May) and to increase $P P F$ when the natural $P P F$ was $<600 \mu \mathrm{mol} \cdot \mathrm{m}^{-2} \cdot \mathrm{s}^{-1}$. All plants were watered daily and fertilized weekly with a complete nutrient solution (Lorenz and Maynard, 1980).

Endodormancy induction treatments. After $45 \mathrm{~d}$ of growth, two hundred uniform plants (having three shoots with 12 or more nodes) were selected and randomly assigned to LD) endodormancy inhibiting) or SD (endodormancy inducing) during May and June. White-covered black cloth was used daily to impose SD starting at $1700 \mathrm{HR}$. Temperatures were maintained at 25/20 \pm 3 ${ }^{\circ} \mathrm{C} \mathrm{D} / \mathrm{N}$ in both photoperiod treatments. Thirty plants were randomly assigned to each of the 2, 4, and 6 treatment weeks in the LD and SD conditions. Eight plants were randomly selected in each treatment for the physiological and MRI measurements, providing a total of 48 plants for this study. The remaining plants were used in other studies.

Physiological Responses. Shoot growth and periderm development on one shoot per plant $(n=8)$ were measured the week before and the week of harvest and the rates are presented for 2 , 4 , and 6 weeks of treatment. Periderm development was determined as described previously (Fennell and Hoover, 1991). Shoot apical meristem (tip) abscission was also monitored throughout the study to determine whether it could be used as a visual indicator of dormancy induction. One shoot per plant in the eight plants assigned to the 6-week treatment was marked and then observed weekly for terminal meristem abscission $(n=8)$. Data are expressed as total number of shoot apical meristems that abscised.

The relative depth of endodormancy was determined for eight plants in each treatment. The leaves were removed and the plants were spur-pruned leaving the first two nodes of each shoot (Fennell et al., 1996). These spur-pruned plants were placed under LD growing conditions. The number of days to budbreak for nodes 1 and 2 on each of three spurs (six buds) on each plant were observed and averaged to provide the number of days to budbreak for each plant $(n=8)$. In addition, single node sections, of one pruned shoot (nodes 3 through 12 from the shoot base origin) taken from each of these plants, were also monitored for endodormancy response. The single-node sections were placed in an individual tube with $5 \mathrm{~mL}$ distilled water, placed in a $5{ }^{\circ} \mathrm{C}$ cooler overnight (to simulate treatment of node sections used for MRI measurements) and then placed in growth chambers with a $15 \mathrm{~h}$ photoperiod at $25 / 20 \pm 1{ }^{\circ} \mathrm{C} \mathrm{D} / \mathrm{N}$ to determine depth of endodormancy by recording the number of days to budbreak. Only whole plant results are presented herein as there was no difference between the depth of endodormancy for the individual node sections and the whole plants.

Dry weights (DWs) of stem and bud tissue were determined in node 6 , from the shoot base origin, of the same shoot used for the MRI sample. The bud was excised from a $1.0 \mathrm{~cm}$ section of node 6 and the two tissues were dried at $70{ }^{\circ} \mathrm{C}$ for 1 week and DW was determined $(\mathrm{n}=8)$.

Nuclear magnetic Resonance imaging. Samples were collected for MRI measurements at 2, 4, or 6 weeks of photoperiod treatment from the same plants that were used for the physiological measurements. Five-centimeter stem sections containing node 5 (numbered from base of the shoot) were harvested for MRI measurements. Node sections for MRI measurements were placed with $1 \mathrm{~mL}$ of distilled water in individual $15-\mathrm{mL}$ plastic culture 
tubes (Fisher, Pittsburgh, Pa.). Samples were shipped with ice (samples separated from the ice by layers of paper to maintain them at $4 \pm 2{ }^{\circ} \mathrm{C}$ ) by overnight express to Beltsville Agricultural Research Center, Beltsville, Md., where MRI measurements were made the same day. Four samples each were collected from LD and SD and sent on $2 \mathrm{~d}$ for each treatment week, so that all samples could be measured on the day of arrival.

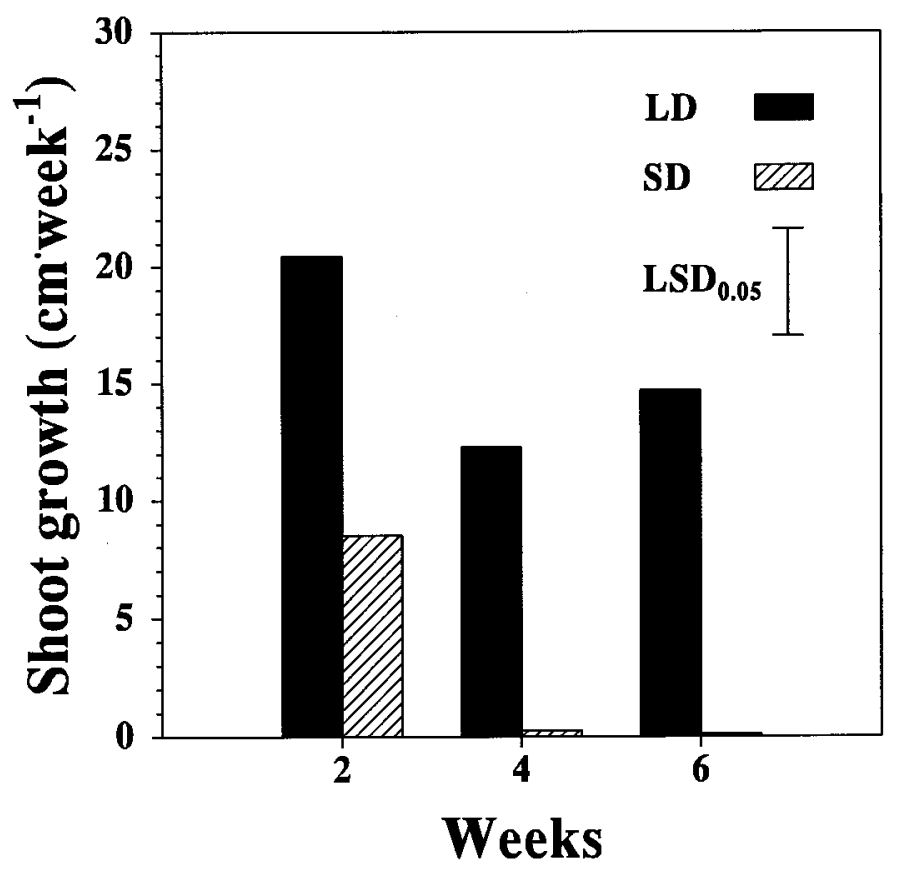

Fig. 1. Shoot growth at 2, 4, or 6 weeks of long photoperiod (LD) or short photoperiod (SD) expressed in centimeters per week. Data are means of eight replications. The SNK least significant difference (LSD) at $P=0.05$ is indicated in the figure.

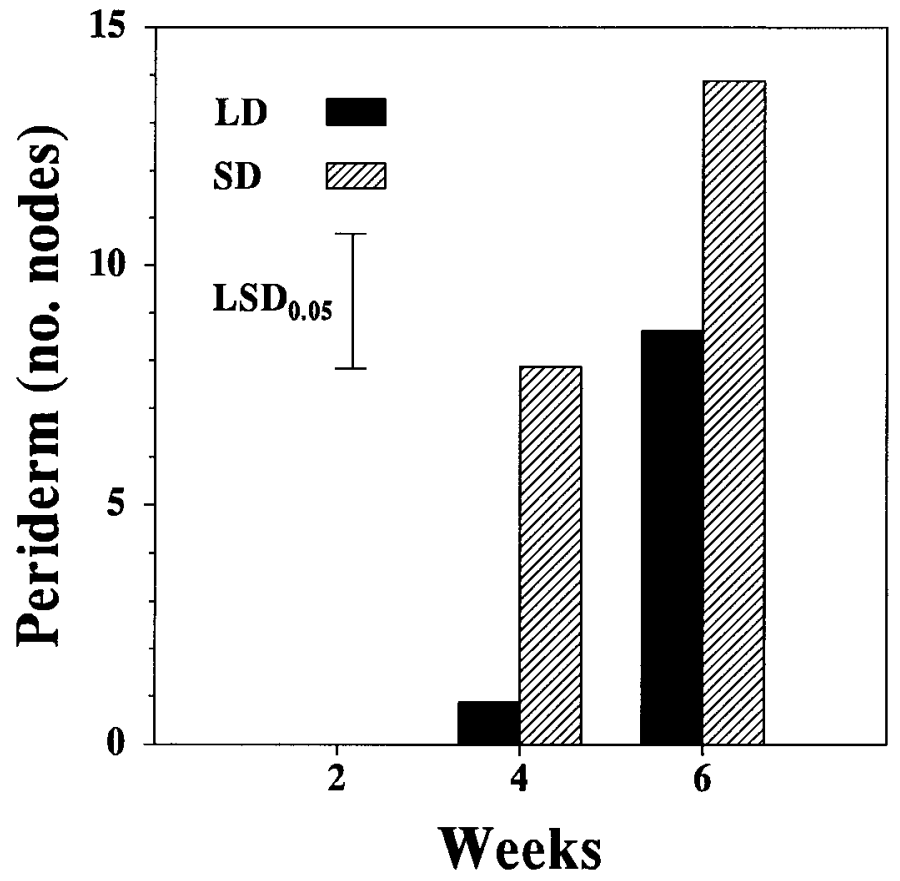

Fig. 2. Periderm development at 2, 4, or 6 weeks of long photoperiod (LD) or short photoperiod (SD) expressed as number of nodes from the base of the shoot. Data are means of eight replications. The SNK least significant difference (LSD) at $P$ $=0.05$ is indicated in the figure.
Node sections were placed in a custom $10 \mathrm{~mm}$ MRI tube for imaging with a Bruker MSL, $400 \mathrm{MHz}(9.4 \mathrm{~T})$ microimaging instrument (Bruker Instr. Co., Bellerica, Mass.). Sixteen $0.5 \mathrm{~mm}$ serial image slices taken perpendicular to the stem axis were made to identify the area containing the center of the primary bud. This area was used for $T_{2}$ imaging and $T_{2}$ times were calculated by nonlinear least square fit to the magnitude images after mean filtering as described in detail by Liu et al. (1993), Millard et al. (1993), and Parmentier et al., (1998). Only samples of similar preparation time, run time, and initial and ending moisture content (Parmentier et al. 1998) were included in the analysis to maintain uniform sample treatment. Thus seven replications were analyzed for each of the LD and SD treatments.

Images were color coded by dividing the $T_{2}$ populations into three groups, based on the range of $\mathrm{T}_{2}$ times determined for the node sections, as follows: <11 ms, 11 to $16 \mathrm{~ms}$, and $>16 \mathrm{~ms}$. $\mathrm{T}_{2}$ times were calculated for bud, gap tissue adjacent to the bud, and the rest of the stem as described above. Data are presented as mean values of seven nodes. The distribution of $\mathrm{T}_{2}$ times within these tissues were determined by separating the total number of pixels (total population of $\mathrm{T}_{2}$ times) measured in a tissue into short or long relations times (Erez et al., 1998; Millard et al., 1995; and Wang et al., 1994). The percentage of long or short $\mathrm{T}_{2}$ of the total population of $\mathrm{T}_{2}$ values were analyzed in bud, gap, and stem tissue for each sample in all LD and SD treatments. Long and short $\mathrm{T}_{2}$ times for the bud and gap tissue were determined according to values reported previously for blueberry and apple buds (Faust et al., 1995; Parmentier et al., 1998). Long and short $\mathrm{T}_{2}$ times for the stem were determined according to $\mathrm{T}_{2}$ times reported previously as free and bound water in apple stems (Wang et al., 1994). Data are presented as a mean of seven replications.

Data analysis. The study was designed as a split plot. Data were subjected to analysis of variance procedures to determine significant treatment effects. A Student-Newman-Kuels (SNK) test, $P$ $=0.05$, was used for mean separation (Cohort, Minneapolis, Minn.) where treatment interactions were significant.

\section{Results}

Physiological response. Plants under both LD and SD maintained their leaves throughout the study. There was some yellowing in the lower leaves of the SD plants after 6 weeks of treatment. The shoots and summer laterals in the LD treated plants continued to grow and showed no apical meristem (tip) abscission. The rate of shoot growth decreased from 20 to $15 \mathrm{~cm}^{*}$ week $^{-1}$ during the 6 weeks of LD treatment (Fig. 1). In contrast, shoot growth decreased markedly after 2 weeks of SD and was minimal after 4 weeks of SD. The summer laterals failed to grow in the SD-treated plants. Shoot tip abscission began during the 5th week of SD and by the 6th week of SD, seven of the eight shoot apical meristems had abscised, terminating growth in those plants.

Periderm developed in LD and SD (Fig. 2). Periderm developed earlier under both SD than LD and was greater at 4 and 6 weeks of SD than LD. The main effects of treatment duration and photoperiod had a significant effect on DW accumulation in bud and stem tissue (Table 1). DW increased significantly with tissue age (week of treatment) in both stem and bud tissue. The buds in SD had greater DW accumulation than in LD treatments. The stem tissue under LD had a greater DW accumulation than under SD.

Time required for budbreak was similar in 2-, 4-, and 6-week LD treatments and time required for budbreak in the 2-week SD 
Table 1. Dry weight of stem and bud at 2, 4 or 6 weeks of long photoperiod (LD) or short photoperiod (SD) treatment.

\begin{tabular}{|c|c|c|c|c|c|c|}
\hline \multirow[b]{3}{*}{ Tissue } & \multicolumn{6}{|c|}{ Dry wt $(\mathrm{mg})^{\mathrm{z}}$} \\
\hline & \multicolumn{2}{|c|}{2 weeks } & \multicolumn{2}{|c|}{4 weeks } & \multicolumn{2}{|c|}{6 weeks } \\
\hline & LD & SD & LD & SD & LD & $\mathrm{SD}$ \\
\hline Bud & $3.5 \pm 0.3$ & $3.6 \pm 0.3$ & $4.4 \pm 0.5$ & $5.2 \pm 0.4$ & $5.3 \pm 1.9$ & $6.5 \pm 2.4$ \\
\hline Stem & $218.0 \pm 12.1$ & $204.4 \pm 16.3$ & $319.9 \pm 43.4$ & $279.6 \pm 20.0$ & $377.3 \pm 23.2$ & $315.0 \pm 20.2$ \\
\hline
\end{tabular}

$\overline{\mathrm{z}}$ Values are expressed as the mean \pm SE of eight replications. Main effects of photoperiod and duration in treatment were significant at $P=0.05$; however, the treatment interaction was nonsignificant.

was not different from the LD treatments (Fig. 3). However, after 4 weeks of SD, the buds appeared to be endodormant. If buds had not begun to grow after $30 \mathrm{~d}$, the plants were left in LD treatment for an additional $30 \mathrm{~d}$ and checked weekly for growth. In that time four buds broke, however shoot growth was limited, the leaves were bronze colored, and the shoots eventually senesced. After 4 and 6 weeks of SD, plants required a prolonged chilling period to break endodormancy (data not presented). A few endodormant plants were left in LD warm temperature for 6 months and showed no budbreak until receiving a chilling treatment.

Mri anaLYsis. In preliminary experiments, $T_{1}$ and $T_{2}$ data were acquired on the same sample. The $\mathrm{T}_{1}$ times were very variable (data not presented), therefore, to minimize sample measurement time, only $T_{2}$ images were used for this study. The distinctive anatomy of the grape vine node was readily discerned in the $T_{2}$ image of a longitudinal section of the node (Fig. 4). The primary bud was located just above the diaphragm in the internode. A secondary bud was visible just below the primary bud. The base of a tendril, that was removed before imaging, could be seen on the opposite side of the stem. The dark areas in the image indicated tissues with very short $\mathrm{T}_{2}(<4 \mathrm{~ms})$ or no water. The transverse image of the node through the center of the primary bud clearly showed the shoot primordium and developing bud scales (Fig. 5). In addition, the epidermis, xylem, phloem, pith,

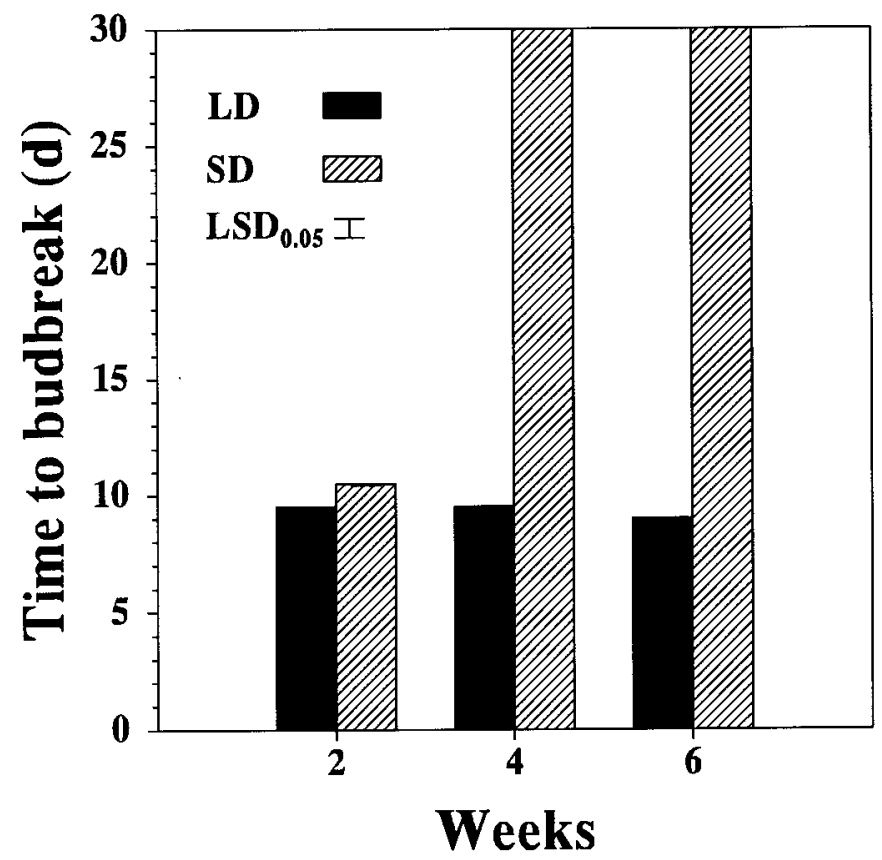

Fig. 3. Number of days to budbreak at 2, 4, or 6 weeks of long photoperiod (LD) or short photoperiod (SD). Data are means of eight replications. The SNK least signigicant difference (LSD) at $P=0.05$ is indicated in the figure. and bud gap and tendril gap tissues were easily discerned.

Overall node response can be determined from $\mathrm{T}_{2}$ relaxation times for the total image (Fig. 6) There was a small decrease in $T_{2}$ times in the LD nodes over the 6 weeks of the study. However, there was a greater decrease in $\mathrm{T}_{2}$ times at 4 and 6 weeks of SD.

Colors were assigned to groups of $\mathrm{T}_{2}$ times based on the range of $T_{2}$ values observed for the entire node image. The tricolored $T_{2}$ images provided a visual map of the state of the water in relation to node anatomy (Fig. 6). In the 2-week LD and SD, the epidermis, cambium, and the exterior regions of the bud had the longest $\mathrm{T}_{2}$ times. As bud scales matured in the SD-treated plants, only the bud meristem could be imaged. Bud meristems and the gap tissues had shorter $T_{2}$ times than the rest of the stem. $T_{2}$ times became so short $(<4 \mathrm{~ms})$ in the bud tissue after 4 weeks of SD that some parts could no longer be imaged (Fig. 6). The epidermal layer of the stem began to disappear from the images after 4 weeks of SD and the pith region could not be imaged in any of the treatments.

These tricolor images indicated differential response in the node tissues and the images were then separated into bud, gap tissue adjacent to the bud, and the conducting portion of the stem tissue (Figs. 5 and 6). Average $\mathrm{T}_{2}$ times were calculated for these separate tissues and analyzed to determine changes associated with maturation and endodormancy induction (Table 2). Analysis of the stem, the gap tissue adjacent to the bud, and the bud indicated that the stem $\mathrm{T}_{2}$ times were always greater than those of the bud and gap tissue. The gap tissue had a decreased $\mathrm{T}_{2}$ time after 2 weeks under SD and continued to decrease with prolonged

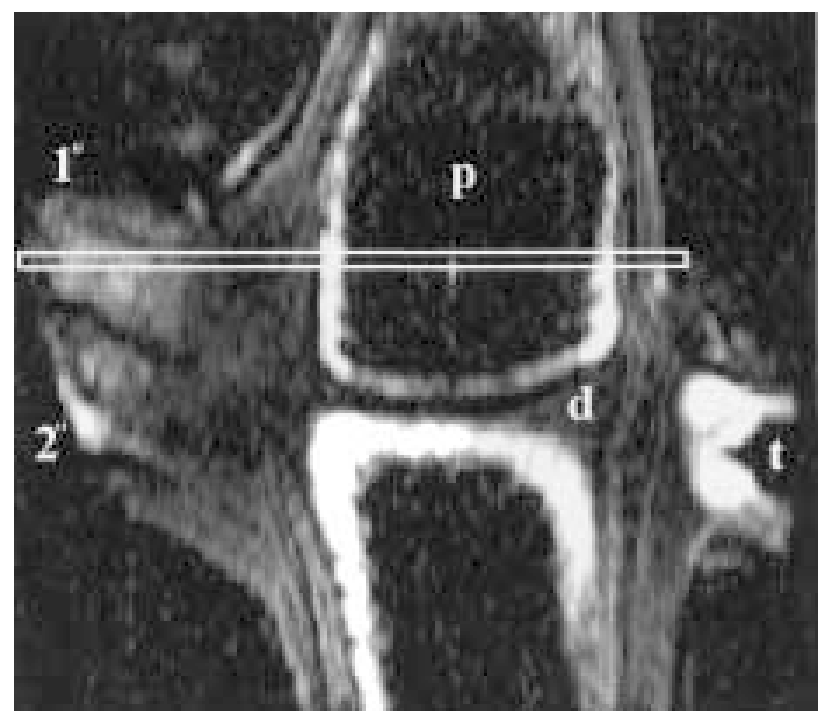

Fig. 4. Magnetic resonance image of a longitudinal section of node. The rectangle indicates the region that was used for $\mathrm{T}_{2}$ measurements; $1^{\circ}=$ primary bud, $2^{\circ}=$ secondary bud, $\mathrm{d}=$ diaphragm, $\mathrm{p}=$ pith, and $\mathrm{t}=$ tendril. 


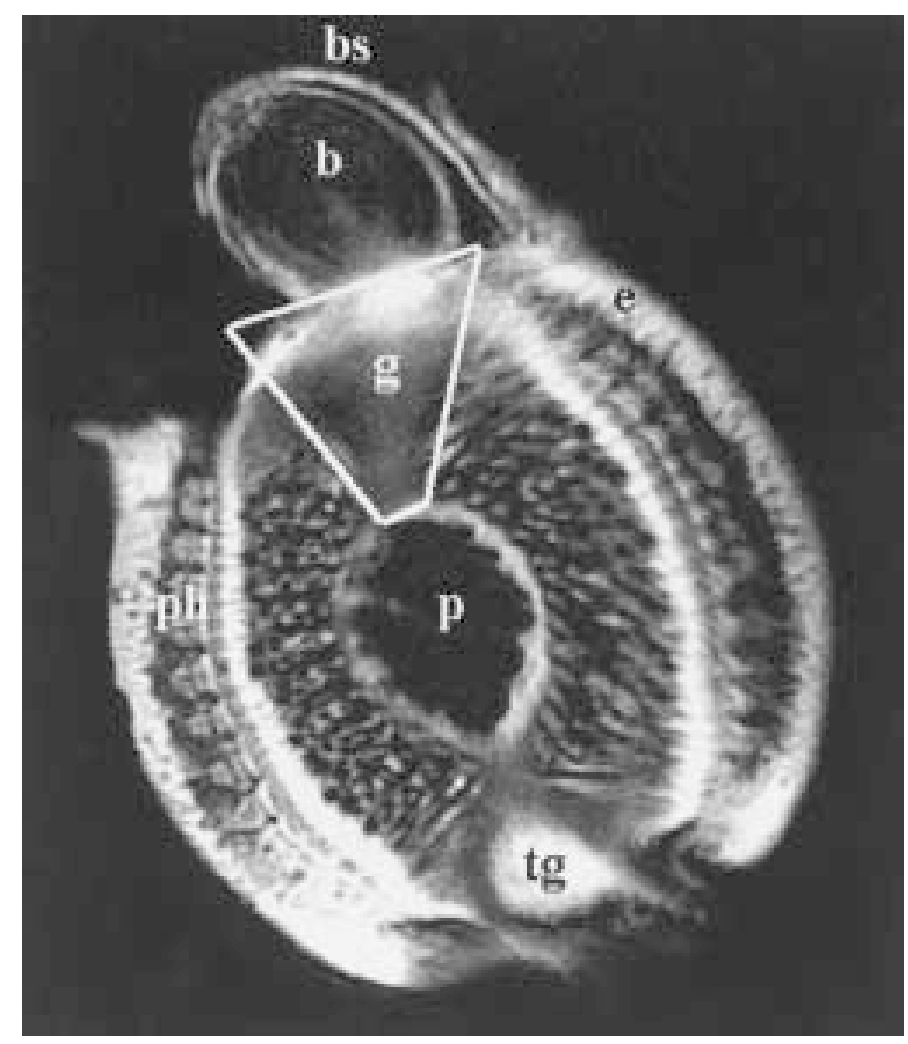

Fig. 5. Magnetic resonance image of node cross section showing bud (b), bud scale (bs), epidermis (e), phloem (ph), xylem (x), cortex/gap tissue (g) adjacent to the bud, pith (p), and tendril gap (tg). Lines delineate the gap region that was analyzed separately from the rest of the stem.

SD treatment. $T_{2}$ times in the stem tissues were decreased by SD and were different from the stem $\mathrm{LDT}_{2}$ times after 4 weeks of SD. Bud $\mathrm{T}_{2}$ times were less than the LD bud $\mathrm{T}_{2}$ times after 6 weeks of SD.

The relative proportion of short and long $\mathrm{T}_{2}$ times are expressed as a percentage of the population of $\mathrm{T}_{2}$ values (Fig. 7). The short and long values were based on values reported previously for endodormant apple, blueberry, and peach (Faust et al., 1995; Rowland et al., 1992) and the range of $T_{2}$ values observed in the present study: $T_{2}<9 \mathrm{~ms}=\operatorname{short} \mathrm{T}_{2}$ and $\mathrm{T}_{2} \geq 9=\operatorname{long} \mathrm{T}_{2}$ values for the bud and gap tissue. $T_{2}$ values for the remainder of the stem tissue were $\mathrm{T}_{2}<15 \mathrm{~ms}=$ short and $\mathrm{T}_{2} \geq 15 \mathrm{~ms}=\operatorname{long} \mathrm{T}_{2}$ (Wang et al., 1994). The proportion of long to short $T_{2}$ times changed little in the bud over the 6 weeks of LD. SD promoted an increase in bud short $\mathrm{T}_{2}$ times at 4 and 6 weeks. In the gap tissue, the proportion of short $\mathrm{T}_{2}$ times increased with prolonged duration of both $\mathrm{LD}$ and $\mathrm{SD}$ but a greater proportion of short $\mathrm{T}_{2}$ were observed in the SD treatments. The remainder of the stem tissue had greater $\mathrm{T}_{2}$ values at all treatments than the bud and gap tissue (Table 2). The proportion of long ( $>15 \mathrm{~ms})$ to short $(<15 \mathrm{~ms}) \mathrm{T}_{2}$ in the LD treatments remained constant over the 6-week period. An increase in the proportion of $\mathrm{T}_{2}$ times $<15 \mathrm{~ms}$ was apparent at 4 and 6 weeks of SD, with the mean value never falling below $13 \mathrm{~ms}$.

\section{Discussion}

In $V$. riparia, LD maintained growth, inhibited development of endodormancy, and allowed effects of increased tissue age to be monitored and separated from dormancy responses. The SD at $25 / 20 \pm 3{ }^{\circ} \mathrm{C} \mathrm{D} / \mathrm{N}$ resulted in growth cessation similar to that observed under a gradually shortened photoperiod (Fennell and Hoover, 1991). SD also promoted shoot tip abscission and endodormancy induction. In poplar (Populus deltoides Bartr. Ex Marsh.), SD promoted endodormancy induction and terminal bud set; however, while terminal bud set occurred at 3 to 4 weeks of SD, endodormancy required 8 to 10 weeks of SD to develop (Jeknic and Chen, 1999). Bud endodormancy in V. riparia was induced at 4 weeks of SD. Shoot tip abscission was observed at 5 weeks of SD and almost all shoot tips had abscised after 6 weeks of SD. Thus, shoot tip abscission was a better morphological indicator of bud endodormancy development in grapes than terminal bud set was as an indicator of endodormancy development in poplar.

DW increased in the buds and stems throughout the experi-

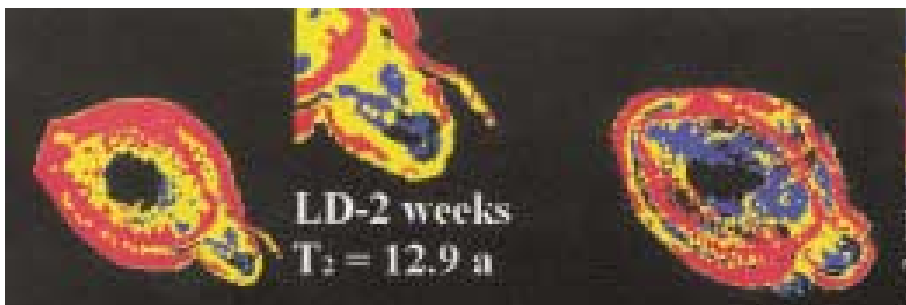

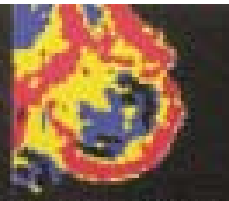

LD-4 weeks $\mathrm{T}_{2}=11.0 \mathrm{~b}$

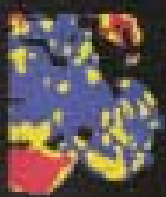

\section{SD -4 weeks}

$\mathrm{T}_{2}=8.5 \mathrm{c}$
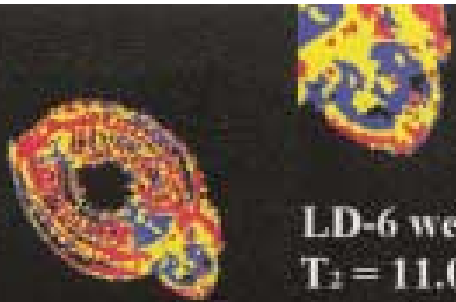

LD:6 weeks $T_{2}=11.0 \mathrm{~b}$

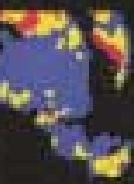

SD-6 weeks $\mathrm{T}_{2}=7.0 \mathrm{c}$

Fig. 6. Color coded $\mathrm{T}_{2}$ images of representative node sections with enlargement of primary bud at 2, 4, or 6 weeks of long photoperiod (LD) or short photoperiod (SD); $\mathrm{T}_{2}<11 \mathrm{~ms}=$ blue; $11 \mathrm{~ms} \leq \mathrm{T}_{2}<16 \mathrm{~ms}=$ yellow; $\mathrm{T}_{2} \geq 16 \mathrm{~ms}=$ red. Mean $\mathrm{T}_{2}$ values $(\mathrm{n}=7)$ for each treatment are indicated below the representative node section Values with different letters are significantly different across all daylength and treatment weeks at $P=0.05$ as determined by SNK mean separation. 

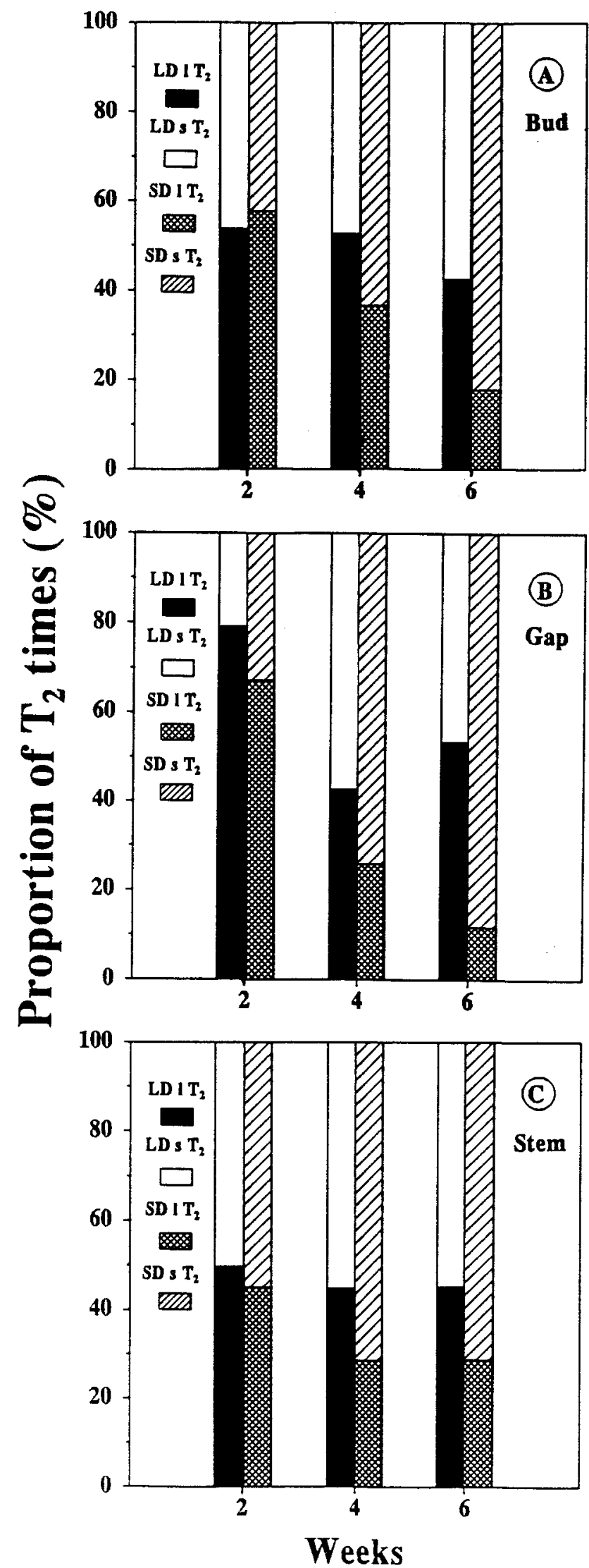

Fig. 7. Proportion of short (s) and long (1) $\mathrm{T}_{2}$ times in (A) bud, (B) gap, and (C) stem tissue at 2, 4, or 6 weeks of LD and SD. Data are expressed as percentage of the total population of $\mathrm{T}_{2}$ relaxation times; $\mathrm{T}_{2}<9 \mathrm{~ms}=\mathrm{s}_{2}$ and $\mathrm{T}_{2} \geq 9=1 \mathrm{~T}_{2}$ values for the bud and gap tissue; $\mathrm{T}_{2}<15 \mathrm{~ms}=\mathrm{s}$ and $\mathrm{T}_{2} \geq 15 \mathrm{~ms}=1 \mathrm{~T}_{2}$ values for stem tissue. Data are means of seven replications. ment. Bud DW increased with SD. In contrast, DW increased with LD in the stems. The increase in DW could be a result of starch deposition, cell wall deposits, and other changes in cell solutes in the stem and bud as have been observed in other grape development and cold hardiness studies (Barka and Audran, 1996, Hamman et al., 1996; Mullins et al., 1992; Pratt and Pool, 1981). An increase in such materials would contribute to decreased $\mathrm{T}_{2}$ times and greater levels of bound to free water as a result of the interaction of water with macromolecules (Faust et al., 1997a, 1997b; Vertucci, 1990; Walter et al., 1992).

MRI has been used to determine anatomical features in a wide variety of plants (Faust et al., 1997b). In the present study, analysis of $\mathrm{T}_{2}$ images at physiologically distinct stages of development provided the opportunity to directly link physiological changes with differential tissue response. The SD-induced phenological and physiological changes observed in grape are reflected in the $T_{2}$ images in the present study. In the natural seasonal cycle, native Wisconsin V. riparia shoots form periderm in late July and early August (Davis and Evert, 1970). As the periderm develops, it isolates the cortex and primary phloem from the conducting secondary phloem (Davis and Evert, 1970; Knudson, 1916; Mullins et al., 1992; Pratt 1974). Subsequently, the separated epidermis, cortex, and primary phloem senesce and become the brown covering on the stems. In the present study, as the periderm developed, the epidermis senesced and disappeared from the $\mathrm{T}_{2}$ images in the 4- and 6- week SD (Fig. 6). The epidermis in the LD treatments was still visible, although it was less apparent in the 6-week LD image which corresponded to the beginning of periderm development in LD shoots. Thus, periderm development, although enhanced by SD, appears to be more related to age/maturation than bud endodormancy. When $\mathrm{T}_{2}$ times are analyzed in the separate areas of the node, decreased $\mathrm{T}_{2}$ times are first noted in the gap region of the stem in the 2-week $\mathrm{SD}$. Changes in the bud and the rest of the stem do not occur until 4 weeks of SD. This parallels visual observations of browning at the node, while the internode region directly below the bud was still green, as periderm development progresses along the shoot.

MRI analysis also provided greater information on the relationship between the state of the water and development of endodormancy. Interaction of water with macromolecules restricts proton motional freedom and is evidenced by short $\mathrm{T}_{1}$ and $\mathrm{T}_{2}$ relaxation times (Faust et al., 1997a, 1997b; Kuntz and Kaufman, 1974; Walter et al., 1992). Short $T_{1}$ and $T_{2}$ relaxation times have been found in endodormant apple, blueberry, grape, and peach buds (Erez et al., 1998; Faust et al., 1991; Fennell et al., 1996; Gardea et al., 1994; Sugiura et al., 1995). T 2 times ranged from $<6 \mathrm{~ms}$ to $<12 \mathrm{~ms}$ in endodormant apple, blueberry, and peach buds (Buban and Faust, 1995; Erez et al., 1998; Faust et al., 1997a; Parmentier et al., 1998; Rowland et al., 1992). In apple, T$_{2}$ values of 6 to $10 \mathrm{~ms}$ were considered bound or associated water and were associated with endodormancy whereas $T_{2}$ values $>15$ ms were associated with free water and growth potential (Faust et al., 1995; Liu et al., 1993; Wang et al., 1994). Endodormant grape buds in this study had a mean $\mathrm{T}_{2}$ time of $5.75 \mathrm{~ms}$. While the $\mathrm{T}_{2}$ times in the paradormant LD buds in this study were greater than those in the SD buds, they also decreased slightly during the prolonged LD treatment. This change in the LD buds indicated that changes occur with maturation/age of the tissue. It also suggested that in experiments where age-matched tissues are not available, care should be taken when using mean $\mathrm{T}_{2}$ times as an indicator of tissue response to a treatment.

Other studies did not examine shoot or stem tissues as thor- 
Table 2. $\mathrm{T}_{2}$ times for bud, leaf gap, and stem tissue at 2, 4, or 6 weeks of long photoperiod (LD) or short photoperiod (SD) treatment.

\begin{tabular}{|c|c|c|c|c|c|c|}
\hline \multirow[b]{3}{*}{ Tissue } & \multicolumn{6}{|c|}{$\mathrm{T}_{2}(\mathrm{~ms})^{\mathrm{z}}$} \\
\hline & \multicolumn{2}{|c|}{2 weeks } & \multicolumn{2}{|c|}{4 weeks } & \multicolumn{2}{|c|}{6 weeks } \\
\hline & LD & SD & LD & SD & LD & $\mathrm{SD}$ \\
\hline Bud & $10.6 a^{y}$ & $10.0 \mathrm{ab}$ & $10.2 \mathrm{ab}$ & $9.3 \mathrm{abc}$ & 8.5 bc & $5.8 \mathrm{~d}$ \\
\hline Leaf gap & $12.8 \mathrm{a}$ & $11.0 \mathrm{~b}$ & $9.6 \mathrm{~b}$ & $7.4 \mathrm{c}$ & $11.0 \mathrm{~b}$ & $5.5 \mathrm{e}$ \\
\hline Stem & $16.1 \mathrm{a}$ & $15.6 \mathrm{a}$ & $16.0 \mathrm{a}$ & $13.6 \mathrm{~b}$ & $16.7 \mathrm{a}$ & $13.2 \mathrm{~b}$ \\
\hline
\end{tabular}

${ }^{\mathrm{z}}$ Values are expressed as the mean of seven replications.

${ }^{\mathrm{y}}$ Mean separation within rows by SNK test at $P=0.05$.

oughly as the bud tissues; however, in apple stems it was noted that there was more free water $\left(T_{2}\right.$ values $\left.>15 \mathrm{~ms}\right)$ in the stems than the adjacent buds. In this study, the LD stem tissue had $\mathrm{T}_{2}$ values similar to the apple stems; however, the $\mathrm{T}_{2}$ times in the $\mathrm{SD}$ stems were shorter after 4 weeks of SD. The $\mathrm{T}_{2}$ times of the stem tissue were always greater than the bud and gap tissue. The $\mathrm{T}_{2}$ times for grape bud and gap tissue in this study are comparable to those found in the vegetative and floral buds of peach and blueberry (Erez et al., 1998; Parmentier et al., 1998; Rowland et al., 1992). However, the $\mathrm{T}_{2}$ times in the SD gap tissue decreased more quickly than the bud tissue upon exposure to SD. The progression of decreasing $\mathrm{T}_{2}$ times in different tissues of the grape node suggested that the SD signal impacted the gap tissue first and then the bud and conducting stem tissue. SD promoted greater changes in the bud and gap tissue $\mathrm{T}_{2}$ times than the stem tissue $\mathrm{T}_{2}$ times during these inductive treatments.

$\mathrm{A} \mathrm{T}_{2}$ time calculated for a given tissue actually represents an average of different $\mathrm{T}_{2}$ time populations that exist within a given anatomical structure (Faust et al., 1997a; Liu et al., 1993). Analyses of $\mathrm{T}_{2}$ populations have led others to propose that the proportion of short vs. long $\mathrm{T}_{2}$ times in a tissue provided a better correlation between state of water and the level of endodormancy or cold acclimation (Erez et al.,1998; Faust et al., 1997a; Liu et al., 1993; Stout and Steponkus, 1978; Sugiura et al., 1995). In apple vegetative buds, an increase in the proportion of longer $\mathrm{T}_{2}$ times was observed upon removal of correlative inhibition (Liu et al., 1993). In peach floral buds, the proportion of water with long or short $\mathrm{T}_{1}$ times changed during the transition from endodormancy to ecodormancy (Sugiura et al., 1995). Erez et al. (1998) found that a greater proportion of short $(<7 \mathrm{~ms}) \mathrm{T}_{2}$ values was observed in endodormant peach flower and vegetative buds. In endodormant blueberry floral buds the water was bound as indicated by very short $\mathrm{T}_{2}(<7 \mathrm{~ms})$ and the proportion of long $\mathrm{T}_{2}$ times (free water) increased with the end of ecodormancy (Parmentier et al., 1998).

In the present study the proportion of short $\mathrm{T}_{2}$ times increased dramatically in SD-treated gap tissue, representing $\approx 90 \%$ of the water after 6 weeks of SD. The ratio of long to short $\mathrm{T}_{2}$ times in the LD buds changed little over the 6 weeks of study. The proportion of short $\mathrm{T}_{2}$ times $(<9 \mathrm{~ms})$ represented the greatest proportion $(82 \%)$ of the $\mathrm{T}_{2}$ population in endodormant buds at 6 weeks of SD. This corresponded to blueberry floral buds, where the proportion of short T2 times ( $<7 \mathrm{~ms}$ ) was about $80 \%$ of the bud water (Parmentier et al., 1998). The blueberry study further indicated that the proportion of long and short $\mathrm{T}_{2}$ times could be used as an indicator of chilling fulfillment when used with $24 \mathrm{~h}$ of forcing conditions (Parmentier et al., 1998). The present study suggested that the proportion of bound to free water in grape buds, as indicated by the long and short $\mathrm{T}_{2}$ times, may provide a better indicator of endodormancy than average $\mathrm{T}_{2}$ and that it may be useful for identifying the transition from paradormant to endodormant.
Use of endodormancy inducing and noninducing photoperiod treatments at $25 / 20 \pm 3{ }^{\circ} \mathrm{C} \mathrm{D} / \mathrm{N}$ allowed separation of maturation effects from endodormancy and eliminated cold acclimation affects that frequently confound dormancy studies. SD induced endodormancy in $V$. riparia within 4 weeks of SD, whereas LD inhibits endodormancy development. SD appeared to promote a cascade of changes, starting in the gap tissue and then the bud and the rest of the stem. MRI analysis indicated that phenological changes could be readily distinguished in the $T_{2}$ images. Changes in the $\mathrm{T}_{2}$ relaxation times reflected these changes, and decreased $\mathrm{T}_{2}$ times were strongly associated with induction of endodormancy. However, $\mathrm{T}_{2}$ times are species and tissue specific and the relative $\mathrm{T}_{2}$ time should not be used as a sole indicator of dormancy status, as $\mathrm{T}_{2}$ may change with tissue age. The proportion of short and long $\mathrm{T}_{2}$ times provided an indication of the bound and free water in a tissue and is a better indicator of dormancy status. Short $\mathrm{T}_{2}$ times indicated a high proportion of bound water is strongly associated with endodormancy in grape buds.

\section{Literature Cited}

Barka, E.A. and J.C. Audran. 1996. Response des vignes champenoises aux temperatures negatives: effet d'un refroidissement controle sur les reserves glucidiques du complexe gemmaire avant et au cours du debourrement. Can. J. Bot. 74:492-505.

Buban, T. and M. Faust. 1995. New aspects of bud dormancy in apple trees. Acta Hort. 395:105-111.

Davis, J.D. and R.F. Evert. 1970. Seasonal phloem development in woody vines. Bot. Gaz. 131:128-138.

Erez, A., M. Faust, and M.J. Line. 1998. Changes in water status in peach buds on induction, development and release from dormancy. Scientia Hort. 73:111-123.

Faust, M., A. Erez, L.J. Rowland, S.Y. Wang, and H.A. Norman. 1997a. Bud dormancy in perennial fruit trees: Physiological basis for dormancy induction maintenance and release. HortScience 32:623-629.

Faust, M., D. Liu, M.J. Line, and G.W. Stutte. 1995. Conversion of bound to free water in endodormancy buds in apple is an incremental process. Acta Hort. 395:113-117.

Faust, M., D. Liu, M.M. Millard, and G.W. Stutte. 1991. Bound versus free water in dormant apple buds-A theory for endodormancy. HortScience 26:887-890.

Faust, M., P.C. Wang, and J. Maas. 1997b. The use of magnetic resonance imaging in plant science. Hort. Rev. 20:225-266.

Fennell A. and E. Hoover. 1991. Photoperiod influences growth, bud dormancy, and cold acclimation in Vitis labruscana and V. riparia. J. Amer. Soc. Hort. Sci. 116:270-273.

Fennell, A., C.F. Wake, and P. Molitor. 1996. Use of 1H-NMR to determine grape bud water state during the photoperiod induction of dormancy. J. Amer. Soc. Hort. Sci. 121:1112-1116.

Gardea, A.A., L.S. Daley, R.L. Kohnert, A.H. Soeldner, L. Ning, P.B. Lombard, and A.N. Azarenko. 1994. Proton NMR signals associated with eco- and endodormancy in winegrape buds. Scientia Hort. 56:339358.

Hamman, R.A., I.E. Dami, T.M. Walsh, and C. Stushnoff. 1996. Sea- 
sonal carbohydrate changes and cold hardiness of Chardonnay and Riesling grapevines. Amer. J. Enol. Viticult. 47:31-36.

Jeknic, Z. and T.H.H. Chen. 1999. Changes in protein profiles of poplar tissues during the induction of bud dormancy by short-day photoperiods. Plant Cell Physiol. 40:25-35.

Knudson, L. 1916. Cambial activity in certain horticultural plants. Torrey Bot. Club Bul. 43:533-537.

Kuntz, I.D. and W. Kaufman. 1974. Hydration of proteins and polypeptides. Adv. Protein Chem. 28:239-345.

Lang, G.A. 1987. Dormancy: A new universal terminology. HortScience 22:817-820

Liu, D., M. Faust, M.M. Millard, M.J. Line, and G.W. Stutte. 1993. States of water in summer-dormant apple buds determined by proton magnetic resonance imaging. J. Amer. Soc. Hort. Sci. 118:632-637.

Lorenz, O.A. and D.N. Maynard. 1980. Knott's vegetable handbook for vegetable growers. Wiley-Interscience, New York.

Millard, M.M., D. Liu, M.J. Line, and M. Faust. 1995. Method for imaging the states of water by nuclear magnetic resonance in low water containing apple bud and stem tissues. J. Amer. Soc. Hort. Sci. 118:628-631.

Mullins, M.G., A. Bouquet, and L.E. Williams. 1992. Biology of the grapevine. Univ. Press, Cambridge, United Kingdom.

Parmentier, C.M., L.J. Rowland, and M.J. Line. 1998. Water status in relation to maintenance and release from dormancy in blueberry flower buds. J. Amer. Soc. Hort. Sci. 123:762-769.
Pratt, C. 1974. Vegetative anatomy of cultivated grapes-A review. Amer. J. Enol. Viticult. 25:131-150.

Pratt, C. and R. M. Pool. 1981. Anatomy of recovery of canes of Vitis vinifera L. from simulated freezing injury. Amer. J. Enol. Viticult. 32:223-227.

Rowland, L.J., D. Liu, M.M. Millard, and M.J. Line. 1992. Magnetic resonance imaging of water in flower buds of blueberry. HortScience 27:339-341

Stout, D.G and P. L. Steponkus. 1978. Nuclear magnetic resonance relaxation times and plasmalemma water exchange in ivy bark. Plant Physiol. 62:636-641.

Sugiura, T., M. Yoshida, J. Magoshi, and S. Ono. 1995. Changes in water status of peach flower buds during endodormancy and ecodormancy measured by differential scanning calorimetry and nuclear magnetic resonance spectroscopy. J. Amer. Soc. Hort. Sci. 120:134-138.

Vertucci, C. W. 1990. Calorimetric studies of the state of water in seed tissues. Biophys. J. 58:1463-1471.

Walter, L., R. Callies, and R. Altenburger. 1992. Studies of plant systems by in vivo NMR spectroscopy, p. 573-610. In: J.D. De Certaines, W.M.M.J. Bovee, and F. Podo (eds.). Magnetic resonance spectroscopy in biology and medicine: Functional and pathological tissue characterization. Pergamon Press, New York.

Wang, S.Y., M. Faust, and M.J. Line. 1994. Apical dominance in apple (Malus domestica Borkh.): The possible role of indole-3-acetic acid (IAA). J. Amer. Soc. Hort. Sci. 119:1215-1221. 